\title{
EXPERIÊNCIA PARA O CLIENTE A PARTIR DE LOJA CONCEITO: UM ESTUDO SOBRE O SEGMENTO DE PERFUMARIA E COSMÉTICOS
}

ANDRÉ IRIBURE RODRIGUES UNIVERSIDADE FEDERAL DO RIO GRANDE DO SUL

PORTO ALEGRE, RIO GRANDE DO SUL, BRASIL E-MAIL: IRIBURE@UFRGS.BR

PAULO DE VITOR CASTILHOS LOPES UNIVERSIDADE FEDERAL DO RIO GRANDE DO SUL PORTO ALEGRE, RIO GRANDE DO SUL, BRASIL

E-MAIL: PVCAS11@HOTMAIL.COM 


\section{EXPERIÊNCIA PARA O CLIENTE A PARTIR DE LOJA CONCEITO: UM ESTUDO SOBRE O SEGMENTO DE PERFUMARIA E COSMÉTICOS}

Resumo: Este artigo visa levantar elementos que contribuam para análise do marketing experiencial como prática contemporânea nas estratégias de marketing e da publicidade. A discussão teórica tensiona elementos do marketing e da publicidade na era das marcas interativas, das Wikibrands, e se apoia em um estudo de caso de produtos no segmento de cosméticos e perfumarias dispostos numa loja conceito. O trabalho de campo por triangulação permitiu considerar os diferenciais do marketing experiencial no incremento de vendas e no vínculo de marcas com seus consumidores.

Palavras-chave: Marketing Experiencial; Publicidade; Lojas Conceito; Marketing; Marca.

\section{LA EXPERIENCIA DEL CLIENTE DESDE EL CONCEPTO DE LA TIENDA: UN ESTUDIO SOBRE EL SEGMENTO DE PERFUMERÍA Y COSMÉTICA}

Resumen: Este artículo tiene como objetivo identificar los elementos que contribuyen al análisis del marketing experiencial como la práctica contemporánea en estrategias de marketing y publicidad. La discusión teórica causa elementos del marketing y la publicidad en la era de las marcas interactivas de Wikibrands, y se basa en un estudio de caso de productos en el segmento de cosméticos y perfumes dispuestos en un concepto de tienda . El trabajo de campo de triangulación permitió considerar el diferencial del marketing experiencial en crecimiento de las ventas y las marcas de enlace con sus consumidores.

Palabras clave: Marketing Experiencial; Publicidad; Tiendas concepto; Marketing; Brand.

\section{EXPERIENCE FOR THE CLIENT ACCORDING TO CONCEPT STORE: A STUDY ABOUT PERFUMERY AND COSMETICS SEGMENT}

Abstract: This article aims to raise elements which contribute for the analy-
ses of experiential marketing as a contemporary practice in marketing stra-
tegies and advertising. The theoretical discussion brings elements from
marketing and advertising in the era of interactive brands, of Wikibrands,
and is based on a case study of products from the perfumery and cosmetics
segments displayed in a concept store. The fieldwork through triangulation 
allowed considering experiential marketing differentials in the sale increment and in the link between brands and their consumers.

Key words: Experiential Marketing; Advertising; Concept Stores; Marketing; Brand. 
Experiência para o cliente a partir de loja conceito: um estudo sobre o segmento de perfumaria e cosméticos

\section{INTRODUÇÃO}

O mercado, em sua contínua transformação, impõe novos desafios aos seus atores nos dias de hoje. O que outrora era regionalizado e pouco suscetível a mudanças, hoje é globalizado e eleva o nível de competitividade entre todos os participantes da cadeia mercantil. Com essa gama de possibilidades, o consumidor avançou em seu modo de consumir e hoje apresenta um nível de criticidade e participação típica de sua geração. Esse cliente não quer apenas o produto, ele busca o envolvimento com a marca por meio de uma experiência de consumo que se estenda desde a escolha até o descarte.

Atender a esse novo perfil de consumidor também é uma tarefa dos profissionais de marketing e de comunicação publicitária, os quais precisam reconhecer tendências e criar e manter vínculos entre marcas e seus clientes.

Moffitt e Dover (2012) definem como Wikibrands processos de gestão, numa era em que o consumidor tem disponível para definir a compra a pontencialidade de investigar até os valores da empresa e, a partir disso, escolher aquela com quem mais tem afinidade. Essa potencial conexão entre marca e consumidor passa também pela inserção do cliente no "universo" da marca. Universo tratado aqui como pontos de contato possíveis para o cliente tanto no meio físico quanto virtual.

Para gerar esse envolvimento, o marketing experiencial oferece ferramentas capazes de gerar diferenciais na interação entre cliente e marca. Ele pode ser realizado por meio de estímulo aos sentidos humanos a visão, audição, olfato, paladar e tato ssim como através de narrativas que envolvam o consumidor.

O marketing experiencial ainda é pouco utilizado pelas marcas, uma vez que outros métodos ainda oferecem segurança para as empresas que não pretendem se arriscar em um mercado tão instável. Contudo, é a velocidade de mudanças tecnológicas e comportamentais que incita a necessidade de novas formas de se relacionar com o consumidor. Para equilibrar essas duas medidas segurança e inovação o modelo de loja conceito aparece como um termômetro para a marca testar novos meios de interação com o seu público-alvo. À medida que esse modelo passa a ser adotado de forma crescente pelas marcas, torna-se relevante identificar elementos de sua estruturação e entender as estratégias que sustentam essa relação entre marcas e con- 
sumidores.

Este texto conta com dados obtidos pelo método de estudo de caso, pois permite tratamento de dados empíricos por triangulação, contando com técnica de observação e entrevistas.

O objeto de estudo escolhido foi uma loja conceito de marca franqueada de perfumaria e cosméticos, localizada num Shopping na cidade de Porto Alegre/RS. Nela foi realizada uma pesquisa de campo numa abordagem qualitativa, composta por entrevista semiestruturada, dividida em dois módulos. O primeiro foi realizado junto às colaboradoras da marca para entender como se dá o processo de geração de experiência para o consumidor. O segundo foi realizado com clientes da marca com o objetivo de analisar a percepção dos estímulos por parte dos clientes. Também foi realizada a observação não participante para analisar como os clientes interagem com os produtos e dispositivos presentes no ponto de venda, permitindo a triangulação com os outros dados de campo.

Para embasar a análise, o referencial teórico utilizado é composto por Kotler e Keller (2006) em se tratando de marketing; Kotler, Kartajaya e Setiawan (2010); Moffitt e Dover (2012); Calixta (2008) são referências para abordar as tendências e desafios do marketing contemporâneo. Para embasar a discussão sobre as sensações na perspectiva da geração de experiências são utilizados autores como Gobé (2002), Lindstrom (2009) (2012), Schmitt (2002). O funcionamento dos sentidos são abordados para, com isso, entender os melhores métodos de gerar incentivos, tendo-se com referência Carter (2012). Neste cenário, é possível realizar uma análise sobre o potencial do marketing experiencial aplicado ao mercado de consumidores de Wikibrands.

\section{CONSTRUÇÃO DE MARCA}

Anteriormente ao marketing experiencial, outros métodos foram utilizados à medida que o mercado de consumo se desenvolvia. Em cada momento um modelo de gestão se tornou o mais adequado, delineando uma história de gestão de marca.

A marca é a representação da empresa para o mercado, indica o seu segmento, intenções e suas expectativas. Também serve como diferenciador perante os concorrentes de setor e confere uma identidade, o que distancia a empresa de uma commodity. Ela é capaz de oferecer características ca- 
Experiência para o cliente a partir de loja conceito: um estudo sobre o segmento de perfumaria e cosméticos

pazes de levar o consumidor a gerar significações ao nível de produção de valor simbólico.

Segundo Kotler, as etapas que a marca precisa percorrer para obter aumento no valor percebido são:

(1) assegurar a identificação da marca entre os clientes e sua associação na mente deles, valendo-se de uma classe de produtos específica ou de uma necessidade do cliente; (2) estabelecer com solidez a totalidade do significado da marca na mente dos clientes, vinculando estrategicamente a ela uma grande quantidade de associações tangíveis e intangíveis; (3) obter as respostas adequadas do cliente em termos de julgamento e sensações relacionados à marca, e (4) adaptar a resposta da marca a fim de criar um relacionamento de fidelidade ativo e intenso entre ela e o cliente (KOTLER; KELLER, 2006, p. 274).

Essas etapas são úteis à construção da marca e somam à análise realizada por Moffitt e Dover (2012), os quais apresentam seis gerações na construção de marca. Segundo os autores, o primeiro estágio tinha o objetivo de identificar a posse. Ele foi sucedido pelo segundo ciclo, o qual tinha a função de demonstrar segurança. O terceiro ciclo se caracteriza pelo desejo do consumidor pela marca. O quarto ciclo já se apresenta em um cenário de consumo pós-massa que busca atender o desejo de nichos, formados por consumidores em busca das características e benefícios do produto. $O$ quinto ciclo carrega consigo as marcas que possuem valores e envolvem os consumidores. A geração mais recente na construção de marca é reconhecida pelo caráter participativo que os clientes possuem em relação às marcas que consomem.

Segundo Martin Lindstrom,

[...] quase todas as principais religiões têm dez pilares comuns subjacentes à sua fundação: uma sensação de pertencimento, uma visão clara, poder sobre os inimigos, apelo sensorial, narração de histórias, grandiosidade, evangelismo, símbolos, mistério e ritual. $E$, exatamente como eu suspeitava, esses pilares têm muito em comum com as nossas marcas e produtos mais amados. (LINDSTROM, 2009, p.100) 
Como se pode observar, tanto Lindstrom (2009) quanto Moffitt e Dover (2012) demonstram que a participação do consumidor está vinculada ao sentimento de envolvimento. A marca precisa demonstrar ao consumidor que ele é importante e que pode participar efetivamente na sua construção. Para que isso aconteça, ela deve abranger o cliente por meio de esforços de marketing que assimilem as necessidades do público que tem afinidade com os valores da marca.

Roberts (2004) faz uma analogia entre marca e pessoa com quem o consumidor pode se envolver emocionalmente. Para o autor, são necessários três elementos para criar o envolvimento. São eles: mistério, sensualidade e intimidade. O mistério é o responsável por criar grandes histórias, mitos e ícones; unir passado, presente, futuro e gerar inspiração aos clientes. A sensualidade envolve os sentidos; audição, visão, olfato, tato e paladar precisam estar presentes na marca que pretende se destacar no mercado. A intimidade serve para assegurar o compromisso, gerar empatia e paixão. A partir desses três elementos, as marcas adquirem ao longo do tempo um espaço importante na vida das pessoas, que passam a protegê-las.

Tavares (2008) reforça a personificação sugerida por Roberts (2004) ao afirmar que

[...] as marcas, à semelhança das pessoas, são dotadas de traços de personalidade. A metáfora da personalidade adotada pela marca era consistente com o que ocorreu nos primórdios da atividade empresarial. [...] A sua personificação correspondeu à crescente necessidade de estabelecer uma identidade com o consumidor para que esse pudesse se relacionar com ela (TAVARES, 2008, p.199).

Assim como as pessoas interagem entre si em busca de experiências, com as marcas é possível desenvolver estratégias que busquem uma "humanização", no sentido de conceder-Ihe uma personalidade que possa gerar empatia junto aos consumidores.

Moffitt e Dover (2012) traçam um perfil da marca com personalidade, presente nessa era de Wikibrands. Segundo os autores 
Experiência para o cliente a partir de loja conceito: um estudo sobre o segmento de perfumaria e cosméticos

As wikibrands dizem respeito a algo maior do que a mídia social ou o novo marketing; trata-se, na verdade, de "negócios sociais" [ um imperativo de negócios. [...] As wikibrands são uma tentativa de estabelecer verdadeiros engajamentos de marca, experiências do cliente e colaborações sociais dentro do âmago de uma organização [...] (MOFFITT; DOVER, 2012, p.21).

Como visto até agora, os autores demonstram a necessidade de gerar relacionamento entre a marca e seus clientes. Para que isso aconteça é firmado um contrato informal e imaginário, no qual estão estipulados itens como reciprocidade, atenção. Caso a marca descumpra esse contrato, o consumidor não hesitará em substituí-la pelo concorrente.

Ainda para matizar a marca no segmento de cosméticos e perfumaria, é ilustrativo salientar que o mercado de cosméticos no Brasil apresentou nos últimos 17 anos crescimento de $10 \%$ ao ano, com o faturamento em 2012 de $\mathrm{R} \$ 34$ bilhões $^{9}$. O poder de compra das classes $C$ e $D$ tem possibilitado esse constante aumento nas vendas, de modo que a classe $C$ correspondeu a $42,6 \%{ }^{10}$ dos gastos em cosméticos e produtos de higiene pessoal no mesmo ano. Para esse público, que corresponde à quase metade de todos os consumidores do setor de cosméticos, a compra é baseada na qualidade dos produtos e na embalagem e tem no seu poder de compra um estímulo positivo devido à conquista dessa posição no mercado de consumo, no entanto não deixam de estar atentos às dificuldades de pagamento e aos juros ${ }^{11}$.

O consumo de produtos do segmento de cosméticos e perfumaria indica motivações na compra além do desejo de conquista da beleza, o que pode ser notado em um comparativo entre as classes sociais, no qual as mulheres de Classe $\mathrm{C}$ buscam o acolhimento da sociedade a partir do uso de cosméticos, o que difere da exclusividade buscada pelas consumidoras de classe $A^{12}$.

9 FOLHA DE SÃO PAULO. Cosméticos no Brasil. Disponível em <http://carodinheiro. blogfolha.uol.com.br/2013/05/29/cosmeticos-no-brasil/> Acesso em 10/11/2013.

10 GAZETA WEB. Classe C é responsável por 42,6\% das compas. Disponível em <http:// gazetaweb.globo.com/gazetadealagoas/noticia.php?c=218035> Acesso em 10/11/2013

11 ESPM. Pesquisa detalha diferenças no perfil de consumo por classe social. Diponível em <http://varejo.espm.br/7396/pesquisa-detalha-diferencas-no-perfil-de-consumo-por-classe-social> Acesso em 10/11/2013

12 SEBRAE. Como vender cosméticos para as classes C e D. Disponível em <http:// www.sebrae.com.br/setor/cosmeticos/o-setor/mercado/consumo/bia-174-41-como-vender-cosmetico-para-as-classes-c-e-d/BIA_17441> Acesso em 10/11/2013 
Os dados apresentados anteriormente indicam a necessidade da marca oferecer aos clientes um ambiente capaz de atender as necessidades de inserção e exclusividade, a partir da segmentação do público e a partir disso gerar valor para ser percebido pelos clientes.

\section{MARKETING EXPERIENCIAL}

O futuro das marcas está baseado na interação com seus consumidores, na troca entre as partes. Para isso, elas precisam gerar experiências positivas para o seu publico-alvo, de modo que ele se identifique ao ponto de completar o vínculo.

Em se tratando de estímulos sensoriais, há muito tempo a visão já é incitada pela publicidade em diversos formatos. Anúncios impressos, mídia out of home, filmes publicitários, entre outros formatos, impactam a todo instante o consumidor. No entanto, o receptor dessa enxurrada visual já desenvolveu mecanismos de bloqueio, uma vez que se tornou impossível absorver todas as informações apresentadas diariamente. Os outros sentidos, em menor intensidade, também são incitados, muitas vezes de forma inconsciente por parte das marcas. Bernd Schmitt destaca a importância de gerar experiência para o consumidor.

Atualmente, os consumidores acham que as características e benefícios funcionais, a qualidade dos produtos e a marca positiva são coisas absolutamente normais. O que eles querem são produtos, comunicação e campanhas de marketing que estimulem os sentidos e que mexam com as emoções e com a cabeça. Querem produtos, comunicação e campanhas que eles consigam incorporar no seu estilo de vida. Querem obter experiência (SCHMITT, 2002, p. 38).

O envolvimento com o consumidor atual pode ser realizado a partir do estímulo dos cinco sentidos visão, audição, olfato, paladar e tato. Eles são os sensores de todas as experiências vivenciadas, as quais podem ser negativas ou positivas. Os sentidos são capazes de realizar ligações sensoriais que afetam diretamente regiões do cérebro como a memória, tão importante para construir a relação de longo prazo entre marca e consumidor. 
Experiência para o cliente a partir de loja conceito: um estudo sobre o segmento de perfumaria e cosméticos

Os matizes de uma imagem, o deleite de um prato diferente, a memória de um som familiar, a carícia macia de um tecido, as associações de velhos aromas estas são as dicas que formam impressões indeléveis em nossa memória emocional (GOBÉ, 2002, p. 116).

Outra possibilidade são as vivências oferecidas pela marca. Podem ser degustações oferecidas aos clientes, viagens, contatos em datas especiais, eventos, situações nas quais a marca passa a gerar um diferencial para o cliente a partir da oferta de uma experiência exclusiva e, com isso, passa a ocupar um lugar cativo na mente e na preferência do cliente.

Para essa construção de longo prazo, a marca precisa estar próxima do cliente o número de vezes necessário para gerar o impacto de forma pertinente, pois a superexposição pode trazer resultados negativos. Em artigo publicado na revista Fast Company ${ }^{13}$, e reproduzida na revista Meio e Mensagem $^{14}$, Rei Inamoto ${ }^{15}$ afirma que as marcas precisam pensar a comunicação não mais no formato $360^{\circ}$, o qual utilizava todas as mídias, mas sim pensar a comunicação 365, de forma a estar todos os dias do ano em contato com o consumidor. Segundo o autor, a marca precisa além de impactar a todo o momento através das mídias, criar envolvimento. Para isso, podem não ser necessárias diversas mídias, mas apenas aquelas que melhor entram em contato com o público-alvo da marca.

\subsection{Os Sentidos}

Antes de dedicar à compreensão para os cinco sentidos é preciso compreendê-los como elementos fundamentais de uma estratégia para chamar a atenção, reter a lembrança e, até, provocar a preferência do consumidor. Desse modo, fica exposta a necessidade de integrar ao planejamento de marketing o estímulo aos sentidos de modo a fazer disso um diferencial da marca capaz de colocá-la em lugar privilegiado na memória do consumidor.

A marca precisa criar estímulos visuais que sejam agradáveis e destoem de toda a carga visual que está nas ruas. O caminho pode estar no design do produto. Ele pode ser um identificador da marca e criar uma relação direta

13 Disponível em <http://www.fastcocreate.com/1683292/the-end-of-advertising-as-we-know-it-and-what-to-do-now> Acessado em 20 de outubro de 2013.

14 Revista Meio e Mensagem, № 1569, ano XXXV, p. 17.

15 Rei Inamoto é vice-presidente e chief creative officer da AKQA 
com o cliente.

O som é responsável por criar uma ambientação que pode interferir no modo como os consumidores interagem com a marca. Martin Lindstrom (2012) afirma que a velocidade da música pode definir se os clientes irão fazer compras de valor maior ou menor se a trilha sonora da loja for mais rápida ou mais lenta, respectivamente.

À medida que acontece a respiração, o olfato capta os odores do ambiente, de modo que ele está permanentemente recebendo estímulos que podem gerar reações no consumidor. Possui forte ligação com a memória, prova disso é a capacidade das pessoas em lembrarem-se dos cheiros de terra molhada, grama cortada, café passado, entre outros exemplos que, mesmo distantes do ambiente em que acontecem, são capazes de serem relembrados por aqueles que possuem essa memória olfativa.

O paladar possui um sistema receptivo semelhante ao olfato capaz de atingir a memória de longo prazo. Importante na escolha de alimentos, este sentido também está ligado a uma prática social de integração entre os indivíduos, que está delimitada nas refeições desses indivíduos com seus grupos de referência.

O tato é responsável por muitas percepções. Geralmente, os clientes preferem tocar o produto antes de comprar. Sentir a maciez, a resistência, acariciar. A experiência vivida pelo estímulo tátil deve ser facilitada pela marca. $O$ toque vai além da necessidade de sentir a textura, o peso do objeto, ele também serve como facilitador para a imaginação em relação à utilização do produto. Segundo Gobé (2002, p. 144) “Uma loja é um parque de diversões! Os objetos e o ambiente devem ser projetados e dispostos para serem experimentados, sentidos e descobertos".

\section{PROCEDIMENTOS METODOLÓGICOS}

Este trabalho foi desenvolvido como um estudo de caso por ser este método adequado à análise de uma prática que está em desenvolvimento, que é o marketing experiencial. $O$ objeto deste estudo é uma empresa do ramo de perfumaria e cosméticos, segmento que possui forte apelo aos sentidos. A escolha do método toma como base o argumento apresentado por Roesch (1999), no qual 
Experiência para o cliente a partir de loja conceito: um estudo sobre o segmento de perfumaria e cosméticos

Alguns aspectos caracterizam o estudo de caso como uma estratégia de pesquisa: permite o estudo de fenômenos em profundidade dentro de seu contexto; é especialmente adequado ao estudo de processos e explora fenômenos com base em vários ângulos (ROESCH, 1999, p. 197).

Para obter parâmetros que possibilitem a análise da marca, foram analisados, no referencial teórico, os conceitos que estão presentes na construção de marca; também foi investigada a contribuição que pode ser agregada pelo marketing experiencial diante do desafio de atender as expectativas de consumidores que querem ser envolvidos e se envolver com a marca.

A importância de analisar a utilização de marketing experiencial pela marca encontra-se no segmento ao qual ela atua. O setor de perfumaria e cosméticos consiste de produtos que oferecem aos seus usuários sensações de prazer e bem-estar. Outro fator importante é o ineditismo, uma vez que a loja conceito analisada neste trabalho, é a única da marca na cidade de Porto Alegre que utiliza esta estratégia e faz parte de um pequeno grupo de lojas da marca no Brasil que estão servindo como piloto para esse novo conceito de loja experiencial.

O que pode ser divulgado sobre a marca é o seu pioneirismo no mercado no setor em que atua. São características abertura de franquias, investimento nos canais de atendimento ao consumidor, no design dos produtos e das suas lojas. E agora, em mais um momento de aperfeiçoamento, a marca desenvolve um novo conceito de ponto de venda com base no marketing experiencial.

\subsection{Métodos de Pesquisa}

Para a validação do esforço de pesquisa teórica sobre a importância do marketing experiencial para as marcas foi realizado um trabalho empírico, composto por pesquisa de campo qualitativa que, é apresentada da seguinte maneira:

Técnicas de pesquisa qualitativa são formas de questões relativamente não estruturadas que permitem uma ampla gama de possíveis respostas. Constituem meios criativos de averiguar as percepções do consumidor que, de outra forma, seriam difíceis de descobrir (KOTLER; KELLER, 2006, p. 105). 
Desse modo, em todas as entrevistas, buscou-se identificar elementos do marketing experiencial a partir dos depoimentos prestados, com roteiro a seguir explicitado, obtendo-se a percepção de colaboradoras e de clientes sobre a experiência vivida na loja.

\subsection{Pesquisa com as Colaboradoras}

O trabalho empírico foi realizado a partir de coleta de dados primários, para o qual três colaboradoras da loja da marca, localizada em um Shopping, em Porto Alegre, responderam a uma série de entrevistas. Para a coleta de dados, as entrevistadas assinaram um documento de autorização para a realização da pesquisa. As identidades das entrevistadas serão mantidas em sigilo, conforme acordado entre as partes.

As questões utilizadas seguiram o modelo de pesquisa não estruturada, na qual

O entrevistado tem liberdade para desenvolver cada situação em qualquer direção que considere adequada. É uma forma de poder explorar mais amplamente uma questão. Em geral, as perguntas são abertas e podem ser respondidas dentro de uma conversação informal (MARCONI; LAKATOS, 1999, p. 96).

\section{Questionário para entrevista com as colaboradoras}

Questionário 1 - As entrevistadas responderam ao roteiro de perguntas que estão no quadro.

01. Qual o objetivo da loja conceito?

02. O que diferencia a loja conceito das lojas tradicionais?

03. Qual o impacto que a loja teve nos clientes? Houve aumento nas vendas?

04. Para a marca há um aumento no valor de marca?

05. A marca investe em mais lojas conceito ou essa é a única loja?

06. Os preços praticados são os mesmos praticados em outras lojas da marca?

07. O número de produtos da loja conceito é o mesmo das lojas tradicionais?

08. Como os clientes reagem aos estímulos sensoriais?

09. Houve aumento na fidelização dos clientes após a implementação da loja conceito? 
Experiência para o cliente a partir de loja conceito: um estudo sobre o segmento de perfumaria e cosméticos

10. Desde a implementação da loja conceito já foi realizada alguma pesquisa com os clientes?

As entrevistas com as colaboradoras da marca foram realizadas na própria loja, pois desse modo foi possível estar no ambiente natural para as entrevistadas, a fim de não interferir nas respostas a partir do local de realização das entrevistas. O tempo de duração também não foi estipulado, ficando a critério de cada entrevistada o tempo necessário para a resposta de cada uma das questões.

\subsection{Entrevista com as Clientes}

Juntamente às informações coletadas na pesquisa com as colaboradoras da marca, buscou-se conhecer o entendimento que os clientes fazem desse novo modelo de loja da marca, baseado em ferramentas de marketing experiencial.

Para isso, foram realizadas entrevistas com duas clientes da marca de cosméticos e perfumaria. Foi seguido o mesmo modelo de coleta, com perguntas diretas baseadas em coleta de dados com abordagem qualitativa. As questões buscaram entender como se dá o consumo e se a loja conceito da marca as impactou e em que aspectos. As duas clientes foram convidadas a visitar a loja conceito, no entanto não foram informadas especificamente sobre o motivo da visita. Após a visita à loja, as entrevistas foram aplicadas nas casas das entrevistadas, a fim de garantir um local tranquilo para as clientes. Do mesmo modo, não foi estipulado tempo para cada reposta, ficando a cargo de cada entrevistada. A identidade das clientes entrevistadas será mantida em sigilo conforme acordado entre as partes, que assinaram autorização de utilização dos dados da entrevista.

\section{Questionário para entrevista com as clientes}

Questionário 2 - O questionário aplicado na entrevista com as clientes da marca.

01. Há quanto tempo você compra produtos da marca?

02. O que a marca representa para você?

03. Por que você compra produtos de cosméticos e perfumaria?

04. Como deve ser uma loja de cosméticos e perfumaria? 
05. Você notou alguma diferença na última visita à loja da marca?

06. Você fez alguma experimentação dos produtos na loja?

07. Quanto ao espaço físico você notou alguma diferença?

08. Você analisou mais produtos do que o habitual?

09. Como foi a experiência dentro da loja?

10. Algo chamou atenção?

11. Você comprou algum produto? Por quê?

O roteiro de perguntas buscou compreender a importância que os produtos cosméticos e de perfumaria possuem para as clientes e, a partir disso, como a marca consegue aumentar a sua importância para o público a partir da oferta de experiências diferenciadas no ponto de venda.

\subsection{Observação Não Participativa}

O terceiro momento da coleta de dados foi composto por observação não-participativa na qual, segundo Marconi e Lakatos, o pesquisador

Presencia o fato, mas não participa dele; não se deixa envolver pelas situações; faz mais o papel de espectador. Isso, porém, não quer dizer que a observação não seja consciente, dirigida, ordenada para um fim determinado. O procedimento tem caráter sistemático (MARCONI; LAKATOS, 1999, p. 92).

Ao todo, seis visitas foram realizadas anteriormente à aplicação da pesquisa, o que permitiu já se ter uma prévia do que se esperava identificar. Para a obtenção dos dados, a observação não participativa foi realizada em uma visita com duração de três horas. Durante esse período foram efetuadas observações sobre como os clientes interagem com os produtos e com os dispositivos criados para gerar experiência para o consumidor. A partir disso, foram realizadas anotações sobre o atendimento, a disposição dos produtos na loja e o comportamento dos consumidores na loja. Desde a entrada na loja até a saída, os clientes foram observados, com discrição para não despertar a desconfiança dos consumidores e, desse modo, modificar a interação com os produtos. A partir disso, anotações foram realizadas a fim de identificar o modo como os clientes são envolvidos pela marca. 
Experiência para o cliente a partir de loja conceito: um estudo sobre o segmento de perfumaria e cosméticos

\subsection{Análise dos Dados}

A análise dos dados contempla os resultados obtidos através de uma tríade composta por entrevista com as colaboradoras da loja conceito, entrevista com as consumidoras e observação não participante. A partir daí, foi realizada uma análise de cada uma das etapas do trabalho empírico.

\subsubsection{Análise de Dados Coletados com as Colaboradoras}

O questionário de perguntas formulado para as colaboradoras da marca procurou entender o propósito de se criar uma loja conceito baseada no marketing experiencial, o quanto ela se diferencia do modelo de lojas utilizadas até então e como os clientes demonstram ter percebido essa mudança.

A entrevista com as colaboradoras também se fez importante, pois, segundo Kotler, Kartajaya e Setiawan (2010)

Os empregados são, na realidade, os consumidores mais próximos das práticas da empresa. Precisam ser fortalecidos com valores autênticos. [...] Os consumidores detectam facilmente quando uma missão de marca não é autêntica. E os empregados detectam com facilidade ainda maior falsos valores nas práticas da empresa (KOTLER; KARTAJAYA; SETIAWAN, 2010, p. 81).

No aspecto apresentado, fica entendido o comprometimento entre empresa e colaboradores. $\mathrm{O}$ conhecimento sobre a marca e a atenção que as colaboradoras dedicam no atendimento aos clientes demonstrou que a missão proposta pela marca é compartilhada por todos os que nela trabalham.

Desse modo, as consultoras já possuem a compreensão sobre o objetivo do novo conceito de loja criado pela marca. Segundo a entrevistada 01, a finalidade da loja conceito é "inovar no mercado de perfumaria. Promover mais conhecimento para o cliente através da experimentação. Oferecer experiência de compra diferenciada". As outras entrevistadas corroboraram com essa afirmação em suas respostas.

Segundo as entrevistadas, a loja conceito se diferencia dos modelos até então utilizados pela marca por meio dos dispositivos de experimentação dispostos na loja, como tablets com conteúdo sobre os produtos, pia para a utilização dos sabonetes da marca, entre outros itens que compõem os estímulos de experiência para o consumidor.

Quando questionadas sobre o impacto que a loja tem alcançado nos clientes, as colaboradoras disseram que a loja tem chamado a atenção dos 
consumidores, desde o leiaute que transmite uma sensação espacial maior ? a gerente de vendas relatou que o espaço físico da loja diminuiu em relação à loja anterior, no entanto os clientes dizem que a loja ficou maior ? até os produtos estão dispostos de uma forma que facilita o acesso e a experimentação. Isso tem levado os clientes a permanecer mais tempo na loja, o que leva a um aumento no consumo. Por causa disso, elas entendem que o valor da marca aumentou, uma vez que todos os estímulos chamam mais a atenção dos clientes. A gerente de vendas destaca que as mudanças acontecem em ciclos de sete anos, contudo essa foi a maior de todas as realizadas.

Ainda, segundo a entrevistada, a loja conceito é um modelo piloto que está sendo utilizado em algumas cidades do Brasil a fim de medir o impacto no consumo dos produtos da marca. Até o momento os resultados são positivos, fato que conduz à segunda fase do planejamento que é o de expansão do modelo de loja experiencial para toda a rede de franqueados.

Quando questionadas sobre a maior permanência dos clientes no interior da loja, as entrevistadas afirmaram que os estímulos sensoriais oferecidos pela marca têm feito com que os clientes dediquem um tempo maior para experimentar os produtos, especialmente os cremes. Uma das consultoras destaca que os clientes gostam da facilidade para experimentar os produtos, além daqueles com aroma. Os produtos que oferecem a sensação do toque, como os sabonetes e creme, têm chamado a atenção dos clientes. A segunda consultora conta que alguns clientes chegam a ficar emocionados com a experiência oferecida pelo produto.

A partir dessa resposta é possível identificar o envolvimento que passa a acontecer entre marca e consumidor, uma vez que o segundo é sensibilizado por uma experiência desenvolvida no ponto-de-venda.

Diante desse diagnóstico, as entrevistadas foram questionadas sobre a possibilidade de aumento na fidelidade dos clientes com base nessas experiências. Segundo as colaboradoras, a fidelização não foi medida, contudo foi notada a maior permanência dos clientes na loja e a consequente elevação do valor de ticket médio ${ }^{16}$.

O aumento no valor médio gasto pelos clientes pode ser um indicador de que os estímulos sensoriais gerados no ponto-de-venda já correspondem a um resultado positivo, alcançado através da oferta de experiência. Contu-

16 Ticket médio é o termo utilizado para identificar o valor médio gasto por cada cliente. Ele é calculado a partir da soma total de venda em um período de tempo e dividido pelo número de pedidos realizados no mesmo período. 
Experiência para o cliente a partir de loja conceito: um estudo sobre o segmento de perfumaria e cosméticos

do, desde a inauguração há mais de um ano desta publicação, a loja conceito realizou apenas uma pesquisa para medir a satisfação dos clientes. Desde então a análise é feita de modo informal a partir da percepção das colaboradoras da loja.

Com base nas informações coletadas junto às colaboradoras da marca, é possível acreditar no impacto positivo alcançado pela marca através do novo conceito de loja, baseada no marketing experiencial. $\mathrm{O}$ aumento na fidelização do cliente parece difícil de medir diante do pouco tempo de implantação do novo modelo de ponto-de-venda, contudo, dados como o aumento do ticket médio indicam que a marca passa a ocupar um local de destaque no desejo de compra dos consumidores.

\subsubsection{Análise de Dados Coletados com as Clientes}

Para entender como os consumidores percebem o novo conceito de loja, será realizada a análise das respostas das clientes sobre a loja conceito. No primeiro momento foi investigado o quanto a marca está presente na vida das clientes entrevistadas.

As clientes pertencentes à Classe $\mathrm{B}^{17}$ e nível de ensino superior completo disseram comprar produtos da marca há bastante tempo, no entanto não há uma regularidade na compra. O intervalo de tempo entre uma visita e outra à loja pode variar bastante. Quando perguntadas sobre o que a marca representa para elas, disseram que os produtos da marca representam qualidade e modernidade aliados a preços acessíveis.

Para entender o que a marca de cosméticos e perfumaria representa para elas, também é preciso entender o motivo que faz esse segmento ser importante. Quando questionadas sobre o motivo que as leva a comprar produtos cosméticos e de perfumaria, a resposta foi que o consumo é baseado no desejo de ficarem mais belas, sendo mencionado o termo vaidade, o que pode demonstrar o elevado nível de carga emotiva no consumo desse tipo de produto.

Para compreender como as clientes se sentem ao entrar em uma loja de cosméticos e perfumaria, foi pedido a elas que definissem o modelo ideal de loja. As respostas foram as seguintes:

17 Conforme a classificação realizada pela Associação Brasileira de Empresas de Pesquisa no instrumento de pesquisa CCEB (Critério de Classificação Econômica Brasil) com data de vigência a partir de 01/10/2012. 
- $\quad$ Entrevistada 01: Deve ser bonita, em um espaço bem iluminado, deve apresentar um ambiente calmo e deve despertar a vontade de usar os produtos.

- $\quad$ Entrevistada 02: Tem que deixar o cliente à vontade para experimentar os produtos do mostruário, ter alguém para explicar como usar os produtos, mas sem ficar tentando empurrar os produtos.

A pergunta sobre o modelo de loja ideal remeteu ao conhecimento da loja da marca, a qual, segundo a entrevistada 01, conhecia desde o lançamento, enquanto a entrevistada 02 disse não ter conhecido anteriormente à pesquisa, pois costuma visitar os quiosques da marca, localizados em shoppings.

Quando questionadas sobre como haviam sido as experiências na loja, elas responderam que experimentaram os produtos durante a visita à loja. Os cremes foram os produtos mais vistos, contudo uma das clientes destacou a experiência vivida com o tablet. Segundo ela, foi muito interessante ouvir música que está relacionada ao perfume. $O$ tipo de experiência que explica os cheiros do perfume, a música calma e a facilidade de uso dessa plataforma fizeram com que ela dedicasse mais tempo para esse produto.

Permaneceram por um período maior que o habitual na loja, pois segundo as entrevistadas, o ambiente da loja oferece uma sensação de liberdade e facilidade de acessar os produtos, além do atendimento atencioso, sem ser intrometido.

Além do espaço físico e da disposição dos produtos, o atendimento foi destacado pelas entrevistadas, definido como leve por uma das clientes. Elas relataram a possibilidade de analisar os produtos com calma, experimentar os que mais chamaram a atenção, de modo que uma delas disse ter gostado de um produto que a fará retornar à loja nos próximos dias para comprar.

Como dito anteriormente, uma das clientes destacou a utilização de música aliada ao perfume, enquanto a outra entrevistada deu ênfase a uma linha de produtos da marca, que no modelo anterior de loja não havia chamado a sua atenção e nessa última visita se destacou, o que a levou a conhecer toda a linha, com destaque para o perfume.

A partir do relato das clientes entrevistadas, é possível analisar a efetiva mudança registrada a partir da loja conceito, uma vez que, apesar de visitarem esporadicamente a loja, gostaram da experiência na última vez que 
Experiência para o cliente a partir de loja conceito: um estudo sobre o segmento de perfumaria e cosméticos

estiveram no ponto-de-venda e dedicaram mais tempo a ele. A impressão deixada nas clientes a partir da nova experiência no interior da loja foi positiva; as entrevistadas destacaram diversas vezes a facilidade de acesso aos produtos, a imersão nos mesmos através dos dispositivos gráficos, sonoros e táteis. $O$ atendimento da loja também foi elogiado por deixá-las à vontade para passear pela loja e conhecer todos os produtos.

A análise das entrevistas realizadas com as consumidoras indica que houve maior interação com os produtos e as experiências vividas na loja permaneceram vivas na memória. Durante vários momentos da entrevista, dispositivos planejados para gerar a experiência, como os fones de ouvido com músicas relativas aos perfumes, eram lembrados pelas clientes.

O que foi relatado pela cliente em relação aos sons, pode ser encontrado na afirmação de Lindstrom (2012), quando o autor diz que a audição cria memórias e transporta o cliente a boas sensações a partir do seu resgate. As repetidas declarações da cliente sobre a experiência sonora encontram no referencial teórico a base para demonstrar à marca a importância de sua utilização.

\subsubsection{Análise de Dados Obtidos Através de Observação}

O terceiro ponto da pesquisa empírica é composto pela observação não participante. Realizada a partir de uma visita, foi possível conferir como os clientes interagem com os estímulos propiciados pela loja. Em geral, chegaram acompanhados, debateram entre si sobre os produtos e fizeram indicações. As consultoras dedicaram atenção aos clientes, elucidaram dúvidas sobre os produtos e demonstraram produtos semelhantes. Também sugeriram a experimentação dos produtos.

Os cremes se destacaram na experimentação dos clientes, contudo os outros produtos também foram experimentados, como a pia dedicada à utilização do sabonete esfoliante e os tablets que apresentam textos e imagens explicativos sobre os perfumes, suas características e composições.

A loja possui iluminação que destaca todos os produtos, feita de forma abrangente da loja e com pontos de luz específicos para cada produto, de forma a destacá-lo. O ambiente da loja é claro, bem iluminado, com os produtos dispostos de maneira que simplifica o acesso a eles; a circulação na loja é facilitada pela disposição dos balcões, com uma ilha central e prateleiras nas laterais. 
Foi possível notar que o formato da loja incentiva a experiência dos consumidores; os clientes são envolvidos por estímulos sensoriais e histórias contadas nos mecanismos audiovisuais.

Através do cruzamento das informações coletadas nas entrevistas e a observação não participante, foi possível ver aplicado os conceitos de marketing experiencial na loja conceito da marca. Dos cinco sentidos apenas o paladar não é explorado pela marca; todos os outros são estimulados durante a visitação à loja. O olfato é estimulado pelas diversas fragrâncias disponíveis na loja; os cremes e a pia de esfoliação aguçam o tato; a audição é avivada a partir de músicas que são reproduzidas em fones de ouvido, escolhidas a partir das fragrâncias que acompanham; o leiaute da loja e os tablets com conteúdos interativos sobre determinados produtos são estímulos à visão. Eles também atuam de forma conectada; as imagens no tablet são sincronizadas à música instrumental que compõe um ambiente sonoro calmo, o texto remete aos cheiros que estão ao alcance do consumidor. Além disso, o consumidor é envolvido em histórias sobre os produtos, disponíveis nos dispositivos de interação.

Este relacionamento criado pela marca tem como objetivo, segundo Kotler e Keller (2006) conceber um relacionamento de longo prazo com o consumidor. Isso pode ser percebido além da loja analisada, pois, ao recuperar-se a história da marca, identifica-se uma postura que se mantém de outros momentos e que se consolida com a loja conceito.

A partir da análise da pesquisa empírica embasada no aporte teórico, foi possível identificar na loja conceito da marca instrumentos capazes de gerar a interação entre marca e consumidor, como apontado por Moffitt e Dover (2012). Por ser um case recente, uma vez que a loja foi inaugurada há pouco mais de um ano desta publicação, o objeto desta pesquisa apresenta potencialidade de elevar o valor da marca de e aumentar a participação no segmento de cosméticos e perfumaria.

\section{CONSIDERAÇÕES FINAIS}

O objetivo deste trabalho foi analisar a aplicação do marketing experiencial na loja conceito de uma marca em específico. Essa proposta se apresenta a partir de um novo paradigma que desafia as marcas a identificarem e proporem alternativas aos consumidores. A resposta do mercado publicitário, ao assimilar novas demandas de anunciantes e consumidores já ocor- 
Experiência para o cliente a partir de loja conceito: um estudo sobre o segmento de perfumaria e cosméticos

rem, sinal disso são os prêmios recebidos por agências de publicidade no principal festival do setor. No Festival de Cannes de 2013, as agências Ogilvy Brasil e McCann Melbourne foram premiadas pelos trabalhos "Dove Real Beleza" e "Dump ways to die", respectivamente, os quais utilizaram do envolvimento com o consumidor para transmitir a sua mensagem. A ligação emocional com o cliente tem se mostrado presente e eficiente nas ações que conseguem gerar diferencial para a marca.

Com o cruzamento dos dados, conjuntamente à análise do embasamento teórico, foi possível constatar que a loja conceito da marca diferencia-se, tanto no segmento de cosméticos e perfumaria quanto no mercado em geral, através da geração de experiências para o consumidor. Foi identificado que a marca pretendia estender o modelo de loja experiencial para toda a rede de franqueados, a partir de 2014, fato que demonstra os resultados positivos que a marca vem alcançando por meio do marketing experiencial.

O marketing experiencial demonstra ser a ferramenta capaz de gerar o diferencial de mercado que os consumidores esperam das marcas. A loja conceito analisada contribui com essa afirmação. Ela tem apresentado à empresa resultados positivos a partir da análise do tempo investido pelos clientes e o valor gasto por eles na loja.

Este trabalho levanta elementos que contribuem com a discussão sobre o marketing experiencial para a gestão de marcas a partir da oferta de ferramentas capazes de atender aos desejos do consumidor presente no marketing contemporâneo, de acordo com o marketing 3.0, conforme Kotler (2010). A expectativa é de deixar uma provocação para os futuros trabalhos acadêmicos ampliarem os estudos sobre a geração de experiências para o consumidor. O desafio não se restringe à academia, estende-se ao mercado, pois cabe às agências de comunicação, aos profissionais de marketing e às empresas criarem novas formas de comunicação com este novo perfil de consumidor.

\section{REFERÊNCIAS}

AAKER, David A.; KUMAR, V.; DAY, George S. Pesquisa de marketing. Tradução: Reynaldo

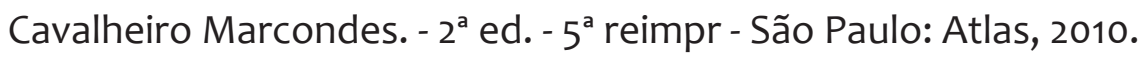

Barômetro de Biodiversidade 2013. Disponível em <http://ethicalbiotrade.org/dl/barometer/UEBT\%20BIODIVERSITY\%2OBAROMETER\%202013\%20PT.pdf> Acesso em: 03 nov. 2013 BAUDRILLARD, Jean. A sociedade de consumo.Tradução: Artur Morão - Lisboa: Edições 70, 2007. p. 47. 
Best Global Brands 2013. Disponível em: <http://www.interbrand.com/pt/best-global-brands/2013/Coca-Cola> Acesso em 28/10/2013.

BLACKWELL, Roger D.; MINIARD Paul W.; ENGEL James F. Comportamento do consumidor. Tradução técnica Eduardo Teixeira Ayrosa (coord.) - São Paulo: Cengage Learning, 2009.

CAMARGO, Pedro Celso Julião de. Comportamento do consumidor: a biologia, anatomia e fisiologia do consumo. Ribeirão Preto, SP: Editora Novo Conceito, 2010.

CARTER, Rita. O livro do cérebro. Tradução: Frances Jones. - Rio de Janeiro: Agir, 2012.

CHARMAZ, Kathy. A construção da teoria fundamentada. Guia prático para análise qualitativa. Tradução: Joice Elisa Costa. - Porto Alegre: Artmed, 2009.

CLARK, Taylor. A febre Starbucks. Tradução: Daniela P. B. Dias - São Paulo: Matrix, 2008. de_logo_corporativo_a_simbo> Acessado em 27de outubro de 2013.

FEIJÓ, Bruno Vieira. A Revolução dos Dados. Exame Pequenas e Médias Empresas, Cidade, n.65, p.37, setembro de 2013.

GOBÉ, Marc. A emoção das marcas: conectando marcas às pessoas. Tradução de Fulvio Lubisco. - Rio de Janeiro: Campus, 2002.

Inauguração nova loja O Boticário - Interativa. Disponível em <http://www.naovivosemesmaltes.com/2013/04/inauguracao-nova-loja-o-boticario.html> Acesso em: 18/11/2013.

KIM, W. Chan; MAUBORGNE, Reneé. A estratégia do oceano azul. Como criar novos mercados e tornar a concorrência irrelevante. Tradução Afonso Celso da Cunha Serra; revisão técnica Consultores Symnetics.- Rio de Janeiro: Elsevier, 2005

KOTLER, Philip; HERMAWAN, Kartajaya; SETIAWAN, Iwan. Marketing 3.0: as forças que estão definindo o novo marketing centrado no ser humano. Tradução Ana Beatriz Rodri-

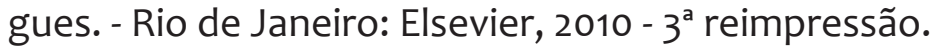

KOTLER, Philip; KELLER, Kevin Lane. Administração de Marketing. Tradução Mônica Rosenberg, Brasil Ramos Fernandes, Cláudia Freire; revisão técnica Dilson Gabriel dos Santos.- 12. ed. - São Paulo: Pearson Prentice Hall, 2006.

LAKATOS. Metodologia científica. 2.ed. - São Paulo: Atlas, 1991.

LINDSTROM, Martin. A lógica do consumo. Verdades e mentidas sobre por que compramos. Tradução Marcello Lino - Rio de Janeiro: Nova Fronteira, 2009.

LINDSTROM, Martin. Brand sense: segredos sensoriais por trás das coisas que compramos. Tradução: Renan Santos - Porto Alegre: Bookman, 2012.

LIPOVETSKY, Gilles. O império do efêmero: a moda e seu destino das sociedades modernas. Tradução Maria Lucia Machado - São Paulo: Companhia das Letras, 2009.

MALHOTRA, Naresh. Pesquisa de marketing. Uma orientação aplicada. Tradução: Lene Belon Ribeiro, Monica Stefani. - Porto Alegre: Bookman, 2012.

Malwee e Listen $\mathrm{X}$, a parceria de sucesso que se fortalece a cada abraço musica. Disponível em: <http://blog.listenx.com.br/2013/01/21/malwee-abraco-musical/> Acesso em 27 de 
Experiência para o cliente a partir de loja conceito: um estudo sobre o segmento de perfumaria e cosméticos

outubro de 2013.

MARCONI, Marina de Andrade; LAKATOS, Eva Maria. Técnicas de pesquisa: planejamento e execução de pesquisas, amostragens e técnicas de pesquisas, elaboração, análise e interpretação de dados. -4.ed. - São Paulo: Atlas,1999

MILLER, Geofrey. Darwin vai às compras. Sexo, evolução e consumo. Tradução: Elena Gaidano - $2^{\mathrm{a}}$ ed. - Rio de Janeiro: Best Seller, 2012.

MOFFITT, Sean; DOVER, Mike. Wikibrands: como reinventar sua empresa em um mercado orientado para os clientes. Tradução: Ronald Saraiva de Menezes. - Porto Alegre: Bookman, 2012.

MOWEN, John C.; MINOR, Michael S. Comportamento do consumidor. Tradução: Vera Jordan. - São Paulo: Pearson Prentice Hall, 2003.

NORMAN, Donald A. Design emocional: por que adoramos (ou detestamos) os objetos do dia a dia. Rio de Janeiro: Rocco; 2008.

Nossa história. Disponível em: < http://nossahistoria.grupoboticario.com.br/pt-br/Paginas/default.aspx > Acessado em 27 de outubro de 2013.

O Touro de Osborne: de logo corporativo a símbolo nacional. Disponível em: <http:// www.choosa.net/pt/community/article/O_touro_de_Osborne_

PETIT, Francesc. Faça você uma marca. - 4ed. - São Paulo: Futura: 2006.

Poemas de Mario Quintana. Disponível em: <http://pensador.uol.com.br/poemas_de_ mario_quintana/> Acesso em 27 de outubro de 2013.

ROBERTS, Kevin. Lovemarks: o futuro além das marcas. Tradução Monica Rosemberg. São Paulo: M. Books do Brasil Editora Ltda. 2005

SCHMITT, Bernd H. Marketing experimental. Tradução: Sara Gedanke. - São Paulo: Nobel, 2002.

TAVARES, Mauro Calixta. Gestão de marcas: construindo marcas de valor. - São Paulo: Harbra, 2008.

Você repórter: Porto Alegre abre a $55^{\mathrm{a}}$ Feira do Livro. Disponível em: $<$ http://diversao.terra.com.br/arte-e-cultura/vc-reporter-porto-alegre-abre-a-55-feira-do-livro,ef9884ce6888a310VgnCLD20000obbcceboaRCRD.html> Acesso em: 27de outubro de 2013. 


\section{André Iribure Rodrigues}

Professor Adjunto na Fabico/UFGRS, Graduado em Comunicação Social - habilitação em Publicidade e Propaganda. Mestre em Comunicação e Informação. Doutor em Comunicação e Informação, todos pela UFRGS, com Doutorado-sanduíche na UFRJ. Vice-diretor da Fabico.

\section{Paulo de Vitor Castilhos Lopes}

Graduado em Comunicação Social - Publicidade e Propaganda pela Fabico/UFRGS. Planejamento na Síncope - Agência de Conteúdo e integrante do Grupo de Planejamento/RS.

RECEBIDO EM: 03/03/2015

APROVADO PARA PUBLICAÇÃO: 06/10/2015 